\title{
A NOÇÃo DE REPRESENTAÇÃO EM PSICANÁLISE: DA METAPSICOLOGIA À PSICOSSOMÁTICA
}

\author{
THE CONCEPT OF REPRESENTATION IN PSYCHOANALYSIS: \\ FROM METAPSYCHOLOGY TO PSYCHOSOMATICS \\ LA NOCIÓN DE REPRESENTACIÓN EN PSICOANÁLISIS: \\ DE LA METAPSICOLOGÍA A LA PSICOSOMÁTICA \\ Rodrigo Sanches Peres* \\ Fátima Caropreso** \\ Richard Theisen Simanke***
}

\section{RESUMO}

Este artigo se propóe, inicialmente, a apresentar sinteticamente os aspectos fundamentais da concepção freudiana original da representação e sua relaçâo com as origens da reflexão metapsicológica. A seguir, são descritos conceitos centrais da psicossomática psicanalítica de Pierre Marty, com destaque para o conceito de mentalização e sua relação com a atividade representacional. Também é abordada a categorizaçáo do campo das neuroses fundamentada pela teoria de Marty. Procura-se, dessa maneira, evidenciar a continuidade entre os fundamentos teóricos da psicossomática psicanalítica e a reflexão metapsicológica freudiana. Busca-se também argumentar que as resistências ainda encontradas, dentro dos meios psicanalíticos mais tradicionais, às inovações teóricas e clínicas da psicossomática psicanalítica resultam de um mal-entendido quanto aos fundamentos teóricos e à filiação conceitual desta última, uma vez que essas críticas frequentemente se justificam por um suposto afastamento entre a psicossomática e o projeto metapsicológico.

Palavras-chave: metapsicologia; teoria psicanalítica; psicossomática; representação.

* Universidade Federal de Uberlândia, Uberlândia, MG, Brasil.

** Universidade Federal de Juiz de Fora, Juiz de Fora, MG, Brasil.

*** Universidade Federal de Juiz de Fora, Juiz de Fora, MG, Brasil. 


\section{Abstract}

First, this paper sets out to synthetically expose some fundamental aspects of Freud's original concept of representation and its relationship with the origins of metapsychological reflection. Next, some central concepts of Pierre Marty's psychoanalytic psychosomatics are described, emphasizing the notion of mentalization and its relations to representational activity. The categorization of the field of neuroses allowed by Marty's theory is also approached. This paper, thus, underline the continuity between the theoretical foundations of psychoanalytic psychosomatics and Freud's metapsychological reflection. It is thus argued that the resistances to psychosomatics' theoretical and clinical innovations that can still be found in the more traditional psychoanalytic milieus result from the misunderstanding of its theoretical foundations and conceptual affiliation, since this criticism is often justified by psychosomatics' supposed removal from the metapsychological project.

Keywords: metapsychology; psychoanalytic theory; psychosomatics; representation.

\section{RESUMEN}

Este trabajo se propone inicialmente a presentar brevemente los aspectos fundamentales de la concepción original de Freud sobre la representación y su relación con los orígenes de la reflexión metapsicológica. A continuación, se describen algunos de los conceptos centrales de la psicosomática psicoanalítica de Pierre Marty, con énfasis en el concepto de mentalización y su relación con la actividad de representación. También se abarca la clasificación del campo de la neurosis permitido por la teoría de Marty. Se busca mostrar la continuidad entre los fundamentos teóricos de la psicosomática psicoanalítica y el pensamiento metapsicológico freudiano. Se busca también sostener que las resistencias que todavía se encuentran, en los medios psicoanalíticos más tradicionales, a las innovaciones teóricas y clínicas de la psicosomática psicoanalítica resultan de un malentendido en cuanto a la afiliación teórica y conceptual de esta última, ya que esta crítica es a menudo justificada por un supuesto alejamiento entre la psicosomática y el proyecto metapsicológico.

Palabras clave: metapsicología; teoría psicoanalítica; psicosomática; representación. 
No texto Sobre a concepção das afasias, publicado em 1891, Freud apresenta sua primeira formulação de uma teoria da representação. Em tal estudo, ele formula a hipótese de que as representaçóes têm como conteúdo básico traços mnêmicos decorrentes de percepçóes precipitadas pelas experiências do sujeito. Esses sistemas de traços mnêmicos, porém, resultam de reorganizaçóes dos estímulos provenientes do mundo externo. Por essa razão, as representações correspondem a uma reconstruçâo complexa e não a um simples retrato ou cópia da realidade externa. Assim, elas podem ser definidas, desde os primórdios da psicanálise, como produções mentais que correspondem a um objeto ausente, tornando-o subjetivamente presente mais uma vez.

Essa reflexão de Freud sobre o conceito de representação fornece o fundamento de toda sua teorização metapsicológica. A partir, sobretudo, de sua tentativa de compreender e tratar as neuroses, ele foi levado a formular uma teoria em que a representaçáo - entendida como um processo mnêmico - se define como a essência do psiquismo e como algo anterior e independente da consciência.

Nesse sentido, Wakefield (1992), por exemplo, observa que a maior contribuição de Freud para a psicologia moderna teria sido a separação por ele estabelecida entre representação e consciência. Esse autor ressalta que, embora não tenha sido quem propriamente "descobriu" o inconsciente, a importância de Freud residiria, principalmente, no fato de ter sido ele quem primeiro forneceu um argumento persuasivo, sistemático e bem fundamentado para a transformação da psicologia de uma ciência da consciência em uma ciência das representaçóes mentais conscientes e inconscientes. Pode-se dizer que, na teoria freudiana, a representação se torna o fato psíquico por excelência, substituindo o papel anteriormente atribuído à consciência como essência do psiquismo pela maior parte das psicologias que lhe antecederam ou lhe eram contemporâneas.

Diante do exposto, torna-se patente a importância da noção de representação em psicanálise. Partindo dessa constatação, o presente estudo tem como objetivo circunscrever mais especificamente essa noção no contexto da metapsicologia freudiana e da psicossomática psicanalítica. Esse objetivo se justifica tendo em vista, por um lado, que a psicossomática psicanalítica parte da metapsicologia freudiana e, de certa forma, vai além dela, ao introduzir novas hipóteses decorrentes da exploraçáo dos aspectos psíquicos das doenças orgânicas. Logo, uma retomada de certos desenvolvimentos da metapsicologia freudiana é capaz de auxiliar na compreensáo dos fundamentos conceituais da psicossomática psicanalítica e evidenciar a continuidade teórica que se verifica entre esta e o pensamento metapsicológico inaugural de Freud, contribuindo, assim, para dissipar os mal-entendidos que ainda alimentam certas resistências dos meios psicanalíticos mais tradicionais às inovações da psicossomática. 
Por outro lado, o objetivo do presente estudo também se justifica pela consideraçáo de que a psicossomática psicanalítica - em que pese o fato de ainda não ter atingido uma difusão tão ampla no meio brasileiro quanto no contexto europeu - representa uma das mais importantes correntes teóricas em psicanálise na atualidade, conforme destacam Aisenstein e Smadja (2001/2003) e Peres e Santos (2012). Proposta originalmente pelo médico francês Pierre Marty e seus colaboradores no início da segunda metade do século passado, seu principal mérito é a sistematização de elementos teóricos necessários para uma melhor delimitação das interaçôes corpo-mente. A psicossomática psicanalítica, assim, viabiliza a ampliação tanto do campo de indicaçóes clínico-terapêuticas da psicanálise quanto de seus horizontes teóricos (Peres, 2006).

Tendo em vista os objetivos estabelecidos, primeiramente serão descritos alguns aspectos cruciais da formulação inicial e do desenvolvimento das concepçóes metapsicológicas de Freud em torno do conceito de representação. A seguir, apresenta-se uma visão geral dos fundamentos teóricos da psicossomática psicanalítica de Pierre Marty, centrada, sobretudo, no conceito de mentalização, a partir do qual é possível tornar mais visíveis suas relaçóes com a teoria freudiana da representaçáo.

\section{O conceito de representaçáo na metapsicologia freudiana}

Em Sobre a concep̧ção das afasias, Freud (1891) compreende a representação como um processo correspondente à última etapa de uma série de reorganizações sucessivas pelas quais as informaçôes sensoriais provenientes do mundo externo passariam desde seu ingresso na periferia do sistema nervoso. Está presente nesse texto a hipótese de que aquilo que percebemos do mundo externo não corresponde exatamente ao mesmo, ou seja, nossas representações não são cópias fiéis dos objetos externos, mas sim o resultado de uma reorganizaçáo que o sistema nervoso opera sobre os estímulos exógenos.

Freud propõe, também no texto em questão, os conceitos de "representação de palavra" e "representação de objeto", os quais desempenham um papel fundamental em sua teoria posterior. A representação de palavra corresponderia a um complexo associativo constituído por imagens acústicas, visuais, quirocinestésicas e glossocinestésicas cujo elemento acústico seria o principal fator organizador. A representação de objeto também corresponderia a um complexo associativo composto por imagens sensoriais variadas no qual o elemento organizador seria, mais frequentemente, a imagem visual. 
A representação de palavra adquiriria significação a partir da sua associação com a representação de objeto, sendo que esta última, por sua vez, adquiriria significado por sua associação com sensaçóes corporais. Em que pese o fato de Freud não esclarecer, em Sobre a concepção das afasias, como as representaçôes de objeto adquiririam significado, a partir de algumas hipóteses apresentadas nos "Estudos sobre a histeria" (Freud \& Breuer, 1895/1998) e no "Projeto de uma psicologia científica” (Freud, 1950/1987), é possível inferir que seriam as sensações corporais que atribuiriam significado a estas. Sendo assim, pode-se dizer que as palavras, em última instância, denotam sensaçóes corporais, associando-se a estas pela via dos objetos (Caropreso \& Simanke, 2011).

Em Sobre a concepção das afasias (1891), no entanto, Freud ainda mantém a identificação entre o psíquico e a consciência, de forma que toda representação é pensada como sendo necessariamente consciente. É no "Projeto de uma psicologia científica", redigido em 1895, mas somente publicado postumamente em 1950, que Freud, após um período de certa indefiniçấo teórica a esse respeito, finalmente desvincula os conceitos de representação e de consciência. As representaçôes passam a ser pensadas como processos que consistiriam em investimentos de traços de memória constituídos a partir de estímulos corporais e de estímulos externos, aos quais a consciência poderia vir ou não a se acrescentar.

Assim, a inconsciência passa a ser o estado original e, em alguns casos, permanente, das representações. A hipótese das associações linguísticas - que, de acordo com o texto de 1891, comporiam a representação de palavra - é, então, retomada para explicar a possibilidade da rememoração consciente. Freud sugere que apenas aquelas representaçóes associadas a palavras poderiam ser rememoradas pela via normal do pensamento, ou seja, a palavra tornaria uma representação suscetível de consciência. Antes da constituição das palavras, o pensamento não se diferenciaria da ação, de maneira que o reinvestimento das imagens de movimento seria a única forma de pensamento consciente presente na origem do psiquismo.

Essas hipóteses formuladas por Freud em 1891 e 1895 continuaram a ser desenvolvidas nos anos posteriores, em especial na carta dirigida a Fliess em 06 de dezembro de 1896, conhecida como carta 52 (Freud, 1950/1998), assim como no sétimo capítulo de "A interpretação dos sonhos" (Freud, 1900/1982) e nos "Artigos metapsicológicos", publicados entre 1915 e 1917. Na carta 52, Freud (1950/1998) inclusive apresenta a hipótese de que os traços mnêmicos sejam sucessivamente reorganizados ao longo do desenvolvimento do indivíduo, de forma que haveria vários níveis de registros nos quais os mesmos traços mnêmicos estariam ordenados segundo diferentes princípios associativos. Assim, diz ele: "a me- 
mória não persiste de maneira simples, mas múltipla, está registrada em diversas variedades de signos" (Freud, 1950/1987, p. 274). Alguns traços mnêmicos, no entanto, não seriam retranscritos nos sistemas subsequentes, devido ao desprazer que seria gerado por essa nova transcrição, permanecendo, portanto, sem acesso à consciência.

As hipóteses de Sobre a concepção das afasias já implicavam que as representaçôes não fornecem um acesso direto ao mundo externo, mas, de certa forma, o reconstroem. A maneira como Freud pensa a memória na carta 52 (1950/1998) faz com que esse acesso ao mundo externo - e também ao corpo, pois os estímulos corporais também seriam registrados pela memória antes de se tornarem conscientes - se torne ainda mais indireto, uma vez que os conteúdos perceptivos seriam submetidos a uma série de reorganizaçóes segundo os diferentes princípios associativos dos sistemas de memória (Caropreso, 2010).

Essa hipótese de uma estratificação da memória é retomada no sétimo capítulo de "A interpretação dos sonhos" (Freud, 1900/1982). Segundo a teoria apresentada em tal texto, o aparelho psíquico seria composto por vários sistemas de memória, os últimos dos quais seriam o sistema inconsciente e o pré-consciente. Freud, assim, elabora hipóteses cada vez mais complexas sobre a possibilidade de acesso de uma representação à consciência. As representaçóes do sistema inconsciente seriam insuscetíveis de se tornarem conscientes no funcionamento psíquico normal de vigília. Parte delas seriam "moções de desejo" inconscientes desde a origem, e outra parte teria sido reprimida, ou seja, embora tenha chegado a integrar o sistema pré-consciente em algum momento, teria sido excluída desse sistema devido ao conflito desencadeado e ao desprazer produzido.

O sistema pré-consciente conteria representaçóes em princípio suscetíveis de se tornarem conscientes, potencialidade essa decorrente de suas vinculaçóes com as palavras. No entanto, Freud sugere que, assim como haveria uma censura entre os sistemas pré-consciente e inconsciente, haveria também uma censura entre os sistemas pré-conscientes e a consciência. Diz ele a respeito do sistema pré-consciente: "suas excitaçóes - certamente obedecendo também a certas regras e, talvez, só depois de superar uma nova censura, mas sem consideração pelo sistema inconsciente - podem alcançar a consciência” (Freud, 1900/1982, p. 602).

Parte das representaçóes pré-conscientes teria o acesso à consciência negado pelo fato de serem excessivamente intensas. Dessa maneira, aquelas representaçôes pré-conscientes que despertassem um desprazer muito intenso seriam alvo da repressão, sendo excluídas para o sistema inconsciente. Outras representaçóes pré-conscientes que fossem muito intensas poderiam permanecer no pré-consciente, mas sem possibilidade de acesso à consciência. Então, na verdade apenas 
parte das representaçóes pré-conscientes seria, de fato, acessível à consciência, e essa possibilidade de acesso à consciência estaria diretamente ligada ao nível de desprazer tolerável pelo psiquismo e pela intensidade das representaçóes.

É possível afirmar, portanto, que, segundo o pensamento freudiano, além de uma parcela muito restrita da nossa vida mental ser acessível à consciência, a fronteira entre aquilo que é passível ou não de se tornar consciente seria móvel, podendo variar, em um mesmo indivíduo, em diferentes momentos da vida, além de variar entre diferentes indivíduos. Ademais, é possível sustentar que, uma vez que o inconsciente se liga diretamente ao corporal e representa a dimensão pulsional do psiquismo, a censura que separa o pré-consciente do inconsciente - e, por extensão, da consciência - nos separa, em maior ou menor grau, do nosso corpo e interfere, assim, na capacidade de simbolização do mesmo.

Já em "O inconsciente", Freud (1915/1982a) retoma os conceitos de "representação de palavra" e de "representação de objeto", formulados em Sobre a concepção das afasias, para explicar a distinção entre os sistemas inconsciente e pré-consciente. Porém, nesse momento, a chamada "representação de objeto" do texto de 1891 passa a ser chamada de "representação de coisa" e Freud passa a designar "representação de objeto" o par constituído pela associação entre a representação de palavra e a representação de coisa. Enquanto no sistema inconsciente apenas esse último tipo de representação estaria presente, o sistema pré-consciente emergiria a partir da associação entre as representaçóes de palavra e as representaçóes de coisa inconscientes. Como parte dessas últimas nunca chegaria a ser associada às palavras, algumas representaçóes permaneceriam no sistema inconsciente, ou seja, não chegariam a fazer parte do pré-consciente. Outras representações de coisa, embora tivessem sido alguma vez integradas ao sistema inconsciente, poderiam perder os seus vínculos com as palavras, de forma a voltarem a fazer parte apenas desse último sistema. O primeiro seria o caso da "repressão primordial" e o segundo da "repressão propriamente dita". Nas palavras de Freud:

o sistema Icc contém as ocupaçóes de coisa dos objetos que sáo as ocupaçôes de objeto primárias e genuínas; o sistema Prcc nasce quando essa representação-coisa é sobre-ocupada pelo enlace com as representaçóes-palavra que lhe correspondem. Tais sobre-ocupaçôes, podemos conjeturar, sáo as que produzem uma organizaçáo psíquica mais alta e possibilitam a rendição do processo primário pelo secundário, que governa no interior do Prcc [...]. A representação não apreendida em palavras, ou o ato psíquico náo sobre-ocupado, fica então para trás, no interior do Icc, como algo reprimido (Freud, 1915/1982a, p. 160). 
Dessa maneira, nesse texto de 1915, Freud explicita a hipótese de que é a perda do vínculo com as palavras que bloqueia a possibilidade de acesso de uma representação à consciência. No artigo "Pulsóes e seus destinos", ele esclarece que seriam os "representantes de pulsão" os alvos do mecanismo de repressão, sendo que esses representantes seriam compostos por uma representação e uma "quota de afeto" (Freud, 1915/1982b). No processo de repressão, esses dois componentes seriam separados. Enquanto o destino da representação seria sempre permanecer inconsciente, a quota de afeto, por sua vez, poderia ser sufocada, vir à tona como um afeto qualitativamente distinto ou ser transformado em angústia.

O surgimento de um sintoma neurótico resultaria do "retorno do reprimido". As representações reprimidas conseguiriam se manifestar no pré-consciente de maneira substitutiva, isto é, por meio de outras palavras, que seriam então símbolos das representaçóes "corretas", de forma que o afeto poderia voltar a ser evocado a partir de representaçóes "erradas". Esse seria o caso da neurose obsessiva. Por outro lado, a representação inconsciente poderia transferir sua excitação para uma inervação corporal, de forma que esta inervação se tornaria um símbolo da representação reprimida, e o afeto originariamente ligado à representação permaneceria sufocado. Esse seria o caso da histeria de conversão. Já na fobia, o afeto voltaria a ser evocado diretamente a partir da representação inconsciente.

Enquanto no funcionamento neurótico o pré-consciente sofreria uma interferência parcial dos processos inconscientes, como se surgissem fendas na censura que separa o sistema inconsciente e o pré-consciente, nas neuroses narcísicas ocorreria um total desinvestimento tanto das representaçóes de objeto pré-conscientes quanto das representaçóes de coisa inconscientes. $\mathrm{O}$ sistema inconsciente e o pré-consciente seriam desinvestidos e o investimento retirado seria novamente direcionado ao eu, o que teria como consequência o retorno a um estado de narcisismo primitivo. Nas neuroses narcísicas - que, com exceção da melancolia, passarão a ser designadas como psicoses após a segunda tópica -, o processo narcísico de desinvestimento das representaçóes de coisa faria com que as representaçóes de palavra se comportassem como aquelas, explicando, assim, as peculiaridades da linguagem nessas afecções (Simanke, 2009).

\section{O conceito de mentalizaçáo na psicossomática psicanalítica}

O termo "mentalização" foi forjado por Marty durante a década de 1970 para fazer referência ao conjunto de representaçóes inscritas no psiquismo. Ele entendia que as representações "constituem a base da vida mental de cada um de 
nós. Habitualmente, durante o dia, por exemplo, fornecem o que chamamos de fantasias. À noite, fornecem os elementos dos sonhos" (Marty, 1996/1998, p. 11). Todavia, é preciso destacar que, para que isso ocorra de fato, ligaçóes longitudinais e transversais devem ser estabelecidas entre as representaçóes no pré-consciente, formando cadeias associativas capazes de estabelecer um diálogo entre aquisiçóes mentais decorrentes de diferentes etapas do desenvolvimento. Na normalidade, esse trabalho psíquico é contínuo. Quando o psiquismo opera sob a égide do pensamento operatório, entretanto, é fragmentado e inconsistente (Smadja, 1995).

O termo "pensamento operatório", também criado por Marty, alude a um tipo de funcionamento psíquico que se situa entre as neuroses e as psicoses. Tal funcionamento, como sintetizam Horn e Almeida (2003), deriva de um comprometimento da capacidade de simbolização e denota, em última análise, a existência de uma carência funcional do psiquismo. Logo, o pensamento operatório tende a se desdobrar em um marcante apagamento de toda expressividade de ordem mental, implicando em pensamentos extremamente superficiais, desprovidos de valor libidinal, excessivamente orientados para a realidade externa e estreitamente vinculados à materialidade dos fatos (Marty \& M’Uzan, 1962/1994).

Marty (1990/1993) afirmou que a suficiência e a disponibilidade das representaçóes do indivíduo são determinantes para a adequação de suas mentalizaçôes. As representaçôes, por seu turno, podem variar quantitativa e qualitativamente de acordo com o funcionamento orgânico ou mental. Quando as representaçóes, a exemplo do que ocorre no pensamento operatório, se mostram constantemente escassas ou inacessíveis, pode-se presumir a existência de dois tipos de problema: 1) um comprometimento das bases perceptivas do sujeito, decorrente de deficiências sensoriais; ou 2) um déficit do seu potencial associativo, resultante de limitaçóes emocionais provocadas, na maioria dos casos, por desarmonias afetivas na primeira infância.

Como exposto anteriormente, Marty (1996/1998), utilizando-se dos conceitos propostos na primeira tópica freudiana, sugere que as representaçôes se associam umas às outras no pré-consciente. Conclui-se, entáo, que, do ponto de vista descritivo, ele entendia - tal como Freud - que as representaçóes de um sujeito podem ser consideradas inconscientes, uma vez que, em última análise, o material pré-consciente não se encontra no plano da consciência. Ao contrário do conteúdo inconsciente propriamente dito, contudo, o material pré-consciente possui, do ponto de vista tópico, uma íntima relação com a consciência, podendo, ao menos parcialmente, se tornar consciente.

Além disso, Marty (1990/1993) adotou a distinção metapsicológica entre as representaçóes de coisa e as representaçóes de palavra e entendia que, se 
isoladas, as primeiras possuiriam um caráter inconsciente e somente poderiam atingir o "índice de qualidade" da consciência quando se associassem às segundas. Portanto, ele sustentava certa primazia das representaçóes de palavra em relaçáo às representações de coisa. Todavia, Marty (1996/1998, p. 17) afirma que, "quando de eventuais desorganizaçóes do pré-consciente, as representaçóes de palavra podem, de maneira patológica, reduzir-se às representaçôes de coisa”. Esse fenômeno ocorre, sobretudo, nas circunstâncias em que as representaçóes de palavra derivam de traços mnêmicos que se assemelham demasiadamente à realidade e reproduzem diretamente as percepçóes. Presos às suas origens sensoriais, os referidos traços não formariam signos, mas, sim, "impressóes fracas" que não subsidiam cadeias associativas (Laplanche $\&$ Pontalis, 1982/2000).

Levando em conta as variaçóes qualitativas e quantitativas das representaçôes, Marty (1990/1993) aponta a existência de dois tipos básicos de mentalizaçôes. Constituídas de representaçóes variadas e enriquecidas por conteúdos afetivos, as "boas mentalizaçôes" viabilizam a adequada descarga das excitações às quais o indivíduo é submetido ao longo da vida. As "más mentalizações", em contrapartida, tornam o aparelho psíquico incapaz de elaborar apropriadamente as tensóes que o acometem e engendram uma acentuada tendência à somatização, visto que são decorrentes de representaçóes insuficientes, esquemáticas e superficiais.

Seguindo esse raciocínio, pode-se concluir que indivíduos "mal mentalizados” são particularmente propensos a doenças físicas. Marty (1990/1993, p. 28) deixa isso claro ao afirmar que "quanto menos o pré-consciente se mostrar rico de representaçóes e de ligaçóes [...], mais a patologia eventual correrá o risco de se situar na vertente somática”. Mas é necessário destacar que, quando se encontra emocionalmente desestruturado, um sujeito dotado de boas mentalizaçóes também pode somatizar. Nesses casos, entretanto, usualmente os sintomas orgânicos são localizados e não-evolutivos, de modo que não colocam em risco a sobrevivência do sujeito.

Reconhecendo a existência de boas e de más mentalizaçôes, Marty (1990/1993) julgou necessário acrescentar novas entidades nosográficas àquelas postuladas pela psicopatologia psicanalítica tradicional e, assim, propôs que as neuroses podem ser divididas em quatro subcategorias básicas: neurose de comportamento, neurose mal mentalizada, neurose de mentalizaçáo incerta e neurose bem mentalizada. A descrição dessas entidades nosográficas, contudo, não deve ser entendida como uma ruptura, mas, sim, como um desenvolvimento da teorização freudiana.

Feito esse esclarecimento, cabe entáo caracterizar cada uma dessas novas entidades nosográficas. A neurose de comportamento pode ser considerada, se- 
gundo Marty (1996/1998), o produto final da existência de uma grande quantidade de representaçóes de coisa e de um reduzido número de representaçóes de palavra no aparelho psíquico, assim como da ocorrência de associações escassas entre as mesmas. Usualmente, um neurótico de comportamento possui uma emotividade primária e uma capacidade de simbolização restrita e, como consequência, tende a utilizar a ação como principal via de expressão dos movimentos inconscientes (Horn, 2007).

A neurose mal mentalizada também sugere uma considerável precariedade funcional do aparelho psíquico. Porém, ao contrário dos neuróticos de comportamento, os neuróticos mal mentalizados são dotados de representaçóes quantitativa e qualitativamente mais adequadas. Justamente por esse motivo, mostram-se aptos, na maioria dos casos, a desenvolver atividades sublimatórias com certa eficiência, apresentando, assim, uma capacidade adaptativa considerável. Vale destacar, contudo, que os neuróticos mal mentalizados dificilmente encontram na linguagem um equivalente do ato (Vieira, 1997).

Já a neurose bem mentalizada encontra-se intimamente relacionada à existência de representaçóes de coisa e de palavra enriquecidas por conteúdos simbólicos. Tais representaçóes relacionam-se umas com as outras, conferindo à vida psíquica grande complexidade. Para Vieira e Castro (2010), os neuróticos bem mentalizados tendem, portanto, a elaborar psiquicamente de forma satisfatória as tensões às quais são submetidos. A despeito disso, possuem um funcionamento defensivo irregular, o que contribui para o desenvolvimento de uma sintomatologia polimorfa. Nesse aspecto, diferenciam-se dos neuróticos típicos, cujo quadro clínico em geral é mais organizado.

A neurose de mentalização incerta, por fim, é considerada uma modalidade intermediária de neurose. Os indivíduos que apresentam um funcionamento psíquico compreensível à luz desse tipo de psicopatologia veiculam com certa frequência representaçôes altamente associativas. Em contrapartida, parecem, em certas situações, possuir um pré-consciente pouco desenvolvido, pois ocasionalmente seus pensamentos se limitam a conteúdos concretos. Logo, é possível propor que os neuróticos de mentalização incerta ora se assemelham aos neuróticos mal mentalizados e ora podem ser comparados aos neuróticos bem mentalizados (Marty, 1996/1998).

A psicossomática psicanalítica parte do pressuposto de que o trabalho psíquico é a mais efetiva defesa do organismo frente às tensôes. Torna-se patente, assim, que as limitaçóes patognomônicas das entidades nosográficas em questáo tendem a influenciar o funcionamento somático. Para Marty (1990/1993), isso pode ser justificado teoricamente da seguinte maneira: 
as neuroses bem mentalizadas abririam regularmente espaço para doenças reversíveis; as neuroses mal mentalizadas e as neuroses de comportamento, para doenças evolutivas; as neuroses de mentalizaçáo incerta, para doenças reversíveis na maioria dos casos, para doenças evolutivas nos casos de desorganizaçóes psíquicas e de repressóes maciças e duráveis das representações (1990/1993, p. 31).

Contudo, diversos autores - tais como Debray (1983/1995) e Ferraz (1997) - salientam que não se pode perder de vista que, segundo a teorização de Marty, a atividade mental é pautada pelo princípio da irregularidade. Tal princípio estabelece que a dinâmica psíquica jamais segue um padrão constante, já que pode ser alterada em virtude da ação de uma vasta gama de fatores. A relativização das referidas hipóteses acerca do papel das mentalizaçóes nos processos somáticos se torna, então, um imperativo. Ademais, o modelo teórico em questão, por ser decorrente da concepção freudiana, não consente com qualquer espécie de fatalismo. Ou seja: postula que o trabalho do aparelho psíquico não pode ser previsto, mas sim apenas compreendido - graças a hipóteses retroativas - a partir de seus determinantes.

\section{Consideraçóes finais}

Em um sentido amplo, pode-se dizer que as origens da teorização freudiana já apontam para uma visão psicossomática do funcionamento mental, tanto normal quanto patológico. Afinal, nunca concebeu a mente como uma realidade totalmente separada do corpo. Apenas para dar alguns exemplos, isso se traduziu, no campo da psicopatologia, em investigações sobre como processos psíquicos podem dar origem a sintomas somáticos (na conversão histérica), sobre como processos psicossomáticos no sentido mais estrito da palavra, sobretudo no campo da vida sexual, podem dar origem a diversos quadros clínicos (nas chamadas neuroses atuais) ou sobre como o corpo comparece decisivamente na conformação da sintomatologia das psicoses (basta pensar na linguagem de órgão esquizofrênica).

A fundamentação metapsicológica dessa visão foi dada, certamente, pela teoria das pulsões, explicitamente definidas como ponto de articulação entre o psíquico e o somático, mas também por uma teoria da representação que, desde os primórdios da metapsicologia, foi pensada como uma hierarquia complexa de processos nervosos excitatórios se estendendo desde a periferia sensório-motora do corpo e das inervações somáticas internas até o nível cortical em que surgem as propriedades psíquicas, passando por sucessivas etapas intermediárias de integração e reorganiza- 
ção. No plano psicológico, a representação, em suas diversas modalidades, realiza a articulação entre o inconsciente - profundamente enraizado no corporal e no pulsional - e as formas mais elaboradas de consciência, passando pelo pré-consciente, no qual surgem as funçôes estruturantes absolutamente cruciais da linguagem.

Resgatar as formulaçôes metapsicológicas originais de Freud sobre a representação e evidenciar sua vinculação com o próprio surgimento da psicossomática psicanalítica é um trabalho que permite não apenas melhor compreender a fundamentação conceitual desta última, mas também precisar o seu lugar no desenvolvimento pós-freudiano das ideias psicanalíticas. Sob essa perspectiva, a psicossomática psicanalítica pode se afigurar como um desdobramento perfeitamente natural das intuiçóes inaugurais da psicanálise freudiana.

Portanto, pode-se concluir que, com o advento da psicossomática psicanalítica, algumas formulaçóes que remetem aos primórdios da psicanálise no que diz respeito à relação entre o psíquico e o somático foram desenvolvidas e explicitadas. O recurso à noção de representação, tal como concebida originalmente pela metapsicologia freudiana, foi essencial para tanto, tendo ensejado a descrição de uma série de entidades nosográficas que não haviam sido concebidas anteriormente. Logo, torna-se patente que são injustificáveis as resistências - classificadas por Ferraz (1997) de "exacerbaçóes idiossincráticas" - que ainda são observadas no seio da psicanálise às descobertas contemporâneas da psicossomática psicanalítica, uma vez que tais resistências partem do princípio de que essas descobertas renegam suas raízes metapsicológicas.

\section{Referências}

Aisenstein, M., \& Smadja, C. (2003). A psicossomática como corrente essencial da psicanálise. In A. Green (Ed.), Psicanálise contemporânea (pp. 407-418). Rio de Janeiro: Imago. (Trabalho original publicado em 2001).

Caropreso, F. S. (2010). Freud e a natureza do psíquico. São Paulo: AnnaBlume/Fapesp.

Caropreso, F. S., \& Simanke, R. T. (2011). Entre o corpo e a consciência: ensaios de interpretação da metapsicologia freudiana. São Carlos: EdUFSCar.

Debray, R. (1995). O equilíbrio psicossomático e um estudo sobre diabéticos. São Paulo: Casa do Psicólogo. (Trabalho original publicado em 1983)

Ferraz, F. C. (1997) Das neuroses atuais à psicossomática. In F. C. Ferraz, \& R. M. Volich (Eds.), Psicossoma: psicossomática psicanalítica (pp. 23-38). São Paulo: Casa do Psicólogo.

Freud, S. (1891). Zur auffassung der aphasien: eine kritische studie. Leipzig: Franz Deuticke.

Freud, S., \& Breuer, J. (1998). Estudios sobre la histeria. In S. Freud. Obras completas, v. 2. Buenos Aires: Amorrortu. (Trabalho original publicado em 1895) 
Freud, S. (1982). Die Traumdeutung. In S. Freud. Studienausgabe, v. 2. Frankfurt: Fischer. (Trabalho original publicado em 1900)

Freud, S. (1982a). Das unbewusste. In S. Freud. Studienausgabe, v. 3. Frankfurt: Fischer. (Trabalho original publicado em 1915)

Freud, S. (1982b). Triebe und Triebschicksale. In S. Freud. Studienausgabe, v. 3. Frankfurt: Fischer. (Trabalho original publicado em 1915)

Freud, S. (1987). Entwurf einer Psychologie. In S. Freud, Gesammelte Werke, v. compl. Frankfurt: Fischer. (Trabalho original publicado em 1950)

Freud, S. (1998). Fragmentos de la correspondencia com Fliess. In S. Freud. Obras completas, v. 1. Buenos Aires: Amorrortu. (Trabalho original publicado em 1950)

Horn, A., \& Almeida, M. C. P. (2003). Sobre as bases freudianas da psicossomática psicanalítica: um estudo sobre as neuroses atuais. Revista Brasileira de Psicanálise, 37(1), 69-84.

Horn, A. (2007). O somático e as experiências corporais. Revista Brasileira de Psicanálise, 41(1), 102-107.

Laplanche, J., \& Pontalis, J. B. (2000). Vocabulário da psicanálise. São Paulo: Martins Fontes. (Trabalho original publicado em 1982)

Marty, P. (1993). A psicossomática do adulto. Porto Alegre: Artes Médicas. (Trabalho original publicado em 1990)

Marty, P. (1998). Mentalização e psicossomática. São Paulo: Casa do Psicólogo. (Trabalho original publicado em 1996)

Marty, P., \& M’Uzan, M. (1994). O pensamento operatório. Revista Brasileira de Psicanálise, 28(1), 165-174. (Trabalho original publicado em 1962)

Peres, R. S. (2006). O corpo na psicanálise contemporânea: sobre as concepçóes psicossomáticas de Pierre Marty e Joyce McDougall. Psicologia Clinica, 18(1), 165-177.

Peres, R. S., \& Santos, M. A. (2012). Psicossomática psicanalítica: intersecçōes entre teoria, pesquisa e clinica. Campinas: Alínea.

Simanke, R. T. (2009). A formação da teoria freudiana das psicoses. São Paulo: Loyola.

Smadja, C. (1995). Le modèle psychosomatique de Pierre Marty. Revue Française de Psychosomatique, 7, 7-25.

Vieira, W. C. (1997). A psicossomática de Pierre Marty. In F. C. Ferraz, \& R. M. Volich (Eds.), Psicossoma: psicossomática psicanalitica (pp. 15-22). São Paulo: Casa do Psicólogo.

Vieira, W. C., \& Castro, L. R. F. (2010). Estudos de psicossomática. São Paulo: Vetor.

Wakefield, J. C. (1992). Freud and cognitive psychology: the conceptual interface. In J. Barron, M. N. Eagle, \& D. L. Wolitzky (Eds.), Interface of psychoanalysis and psychology (pp. 77-98). Washington: American Psychological Association.

Recebido em 25 de março de 2013

Aceito para publicaçáo em 12 de dezembro de 2013

DOI: $10.1590 / 0103-56652015000100009$

Psic. Clin., Rio de Janeiro, vol. 27, N.I, P. I6I - I74, 2015 